\title{
PREPARING FOR GENERATION Z: HOW CAN TECHNOLOGY ENHANCED LEARNING BE FIRMLY EMBEDDED IN OUR STUDENTS' LEARNING EXPERIENCE? A CASE STUDY FROM ABERTAY UNIVERSITY
}

\author{
A.D. Robertson \\ Abertay University (UNITED KINGDOM)
}

\begin{abstract}
Abertay is a relatively small, modern university (undergraduate population of around 4000) with a wide portfolio and a diverse student population. Around $35 \%$ of our students are direct entry from local partner colleges to years 2 and 3 of our programmes and a significant number are first generation higher education within their families. As such, partnership working with colleges and support to aid student transitions are key aspects of Abertay's provision. Since 2013/14, the university has developed and implemented a new Teaching and Learning Enhancement strategy that has catalysed wholescale transformation across the institution. This paper provides an overview of technology enhanced learning at the university with the drivers for change being to the quality of our students' learning experience, improve student retention and progression and enhance learners' engagement.
\end{abstract}

Keywords: technology enhanced learning, learning analytics, student engagement.

\section{INTRODUCTION}

This paper provides an overview of the development of technology enhanced learning at Abertay University which is a relatively small (undergraduate population of around 4000), modern university in Scotland, UK. Since 2013/14 the university has been through a period of significant change to its pedagogic approach, particularly in terms of curricula, assessment and feedback and supporting academic staff development to implement these changes. The drivers for change are in response to the desire to ensure the continuation of providing a distinctive high quality student learning experience that is appropriate for our context, our learners and changes to the higher education sector, including reduced public funding, increased marketisation etc. Technology has been key to supporting delivery, assessing and supporting our students.

In terms of context, several points are worth highlighting. For its size, Abertay offers a relatively broad portfolio structured around three Academic Schools: the School of Design and Informatics, School of Science and Dundee Business School. Subjects taught include: Computer Gaming, Cybersecurity, Sociology, Psychology, Law, Biomedical Science, Accounting, Marketing etc. The student population is also varied such that over $80 \%$ of our students are from Scotland, about $15 \%$ from the EU and the rest are fee paying students from the rest of the UK and outside Europe. Almost all fee paying students are within the School of Design and Informatics. Around 35\% of our students enter directly to years 2 and 3 of our programmes from local partner colleges and a significant number of our students are first generation higher education within their families. As such, partnership working with colleges and support to aid student transitions are key aspects of Abertay's provision. Over the last three years the university has been successful in significantly enhancing the number of students studying computing-related undergraduate degrees at Abertay such as Computer Games Technology, Computer Arts and Cybersecurity. This has resulted in the university hiring a number of new academic staff to support these growth subjects and many of these staff are either early career academics and/or from industry. This means that there has been an urgency to provide these new staff with the necessary support and development of their pedagogic knowledge/ skills.

\subsection{The generational dimension}

School leavers today are from so-called Generation $Z$ and our academic staff are composed of a combination of Millenials (early career staff), Generation $X$ and a rapidly declining proportion of Baby Boomers. Each of these generations have particular traits and experiences and it is important to understand these if universities are to realise the potential of their students and staff. Taking our students first, Generation Z has no experience of living without the internet and have been brought up with 
unparalleled access to data and information [1], [2]. They are extremely proficient at multi-tasking using a variety of internet enabled devices including smartphone, tablet, laptop and TV. This means, however, that their attention span is extremely short and this can be witnessed in our university's lecture theatres as students become distracted and go online. Our students today want to become active participants on the learning process- although they are digitally very literate they still value face to face interaction and enjoy collaborative working. Advances in technology enhanced learning coupled with new learning space designs are providing educators with new opportunities to provide flexible modes of delivery and active learning in the classroom.

There is a tension, however, as many academic staff are comfortable with, and often prefer, more traditional forms of teaching i.e. lectures and tutorials. This is particularly the case amongst older staff. Millenial and Generation X staff are more open to change and indeed many early career staff are leading these innovations with their students as they see the positive impact it can have on their depth of learning and active pedagogies are more in line with their own preferred learning styles.

\subsection{The sticky campus}

Aligned with notions of active learning and helping our students realise their potential is the ethos of the so-called "sticky campus". This phrase originated in New Zealand following the earthquakes in Christchurch in 2011 and subsequent rebuilding of the University of Canterbury campus. The architects recognised the importance of providing informal social learning spaces and this aligns well with the academic literature in terms of factors that improve student retention, progression and attainment i.e. a sense of belonging, interactions with peers and staff, deep approaches to learning, feedback and feedforward etc [3].

Over the last three years, Abertay has bought into the Sticky Campus concept to drive forward Estate and IT infrastructure development [4]. This has included trialling new experimental learning spaces, installing new science laboratories, completely refurbishing the university library, upgrading wifi and enhancing power to support students bringing their own devices on campus. The Abertay Sticky Campus case study has been the focus of several invited conferences talks and published articles.

\section{TAKING A MORE STRATEGIC APPROACH TO EMBEDDING TECHNOLOGY ENHANCED LEARNING}

A key factor in implementing Abertay's teaching and learning enhancement strategy has been to take a strategic approach to embedding technology enhanced learning across the institution. Prior to 2013/14, the Technology Enhanced Learning Support team was part of Information Services and provided responsive support to individual academic staff. It was decided by the University Executive that it was necessary to integrate pedagogical support and technology enhanced learning support for staff within the new academic development professional service; Teaching and Learning Enhancement to create a more holistic, effective academic-oriented service as the Director of Teaching and Learning Enhancement reports directly to the Deputy Vice Chancellor (Academic). As such, the Technology Enhanced Learning Support team moved to TLE and this move has proven very successful overall. Partnership working with Information Services has continued with clear roles and responsibilities.

To support the move, a University working group was established in 2014 composed of key internal stakeholders (academic Schools, Professional Services and students) to set strategic priorities coupled with a top down steer from the university executive in terms of the need for alignment with the overall university strategy and KPIs around student attainment, employability, progression and quality. Given this context, the group identified the following strategic priorities for technology enhanced learning at Abertay going forward:

- New learning spaces

- Assessment and Feedback

- Learning Analytics

- Student Engagement 


\section{LEARNING SPACES}

Abertay has provided a significant amount of support to staff in the use of the new learning spaces by central Professional Services namely Teaching and Learning Enhancement supported by Information Services, to ensure staff who teach in the new spaces are adequately trained in the use of technologies available. The University conducted a scoping exercise in spring 2016 to establish priorities in the area of new learning spaces and also to identify examples of good practice. Several staff members were already using problem-based learning in their teaching but struggling with existing spaces so they were keen to take part in the pilot. In total 13 academic staff from all of the Schools agreed to take part with their students in the trial of Abertay's new Collaborative Learning Suite (CLS) in academic year 2016/17. The use of academic champions has been a critical part of the strategy to help ensure buy-in from staff and the champions have helped to inform the support provided by Professional Services. A report on the trial of the CLS and the experiences of staff with their students has been published within the book "Creating the Digital Campus- active learning spaces and technology" [5].

From term 2 of 2016/17, the CLS was opened up for general booking through the Timetabling system but staff requesting to use the room were required to book a training session with the Teaching and Learning Enhancement team in advance to ensure they were sufficiently trained on the system.

The various staff development activities can be summarised as follows:

- Awareness raising- including promotion of the new facilities, posters, banners, and running staff developments sessions, monthly teaching and learning seminars and the new lecturer teaching and learning programme all ran in the CLS. The new facilities also feature prominently during Open Days with the aim of encouraging students to apply to the university.

- Improving knowledge and understanding- an initial two day training session for the CLS was run in September 2016 facilitated by an external consultant (Duncan Peberdy) supplemented by follow up drop-in sessions and online plus use of the CLS within the new lecturer programme. Additional training for the digital technologies available in the new science laboratories was also provided. Encouraging the sharing of good practice amongst staff in the use of the new spaces has also been encouraged e.g. through the original 13 academic volunteers as mentors.

- Troubleshooting- classroom support, one to one, user guides.

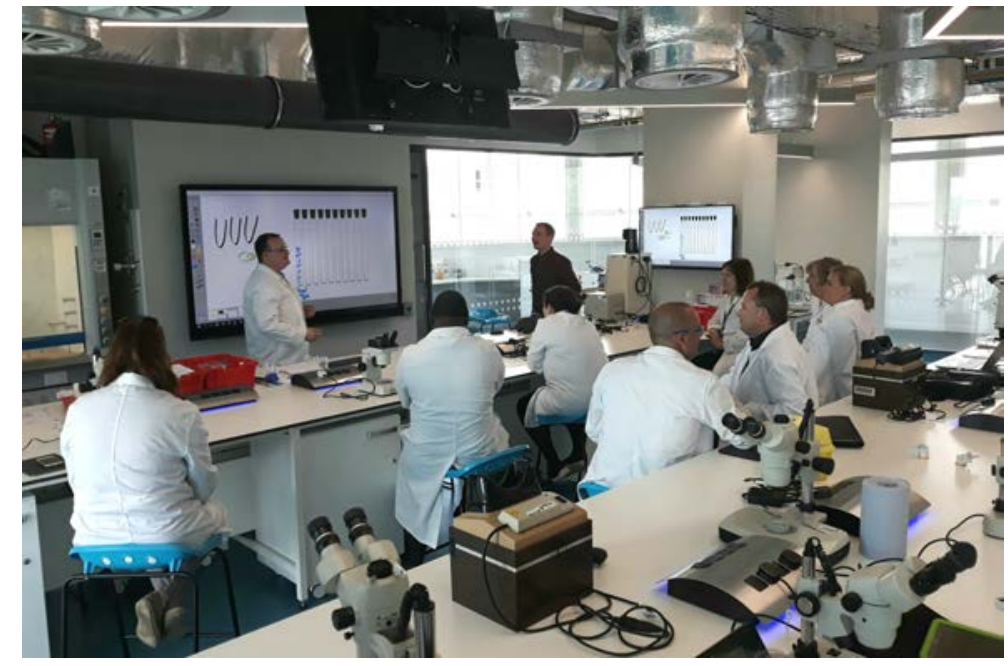

Figure 1. Staff development session on new learning technologies

\section{ELECTRONIC MANAGEMENT OF ASSESSMENT}

Enhancing assessment and feedback policy and practice at Abertay was one of the three pillars of the University's Teaching and Learning Enhancement strategy approved in December 2013. Since then, significant resource was put into going back to first principles and implementing a suite of changes such as a new assessment policy with strict feedback turnaround times, number of units of assessment etc; new literal grading scale, introduction of GPA to calculate honours degree classifications; formal recognition of certain co-curricular achievements (introduction of the HEAR, Higher Education Achievement Report, [6]) and, Electronic Management of Assessment (EMA). Student satisfaction in 
previous years had been poor citing concerns around consistency of the amount and quality of feedback provided by staff, turnaround times, lack of formative feedback etc. Key to the success of addressing these concerns has been the introduction of EMA. With a very small number of exceptions all student coursework is submitted electronically and feedback is provided electronically. End of term exams still tend to be paper-based although the university is doing ongoing trials of online exams.

In terms of successfully implementing EMA, winning hearts and minds of staff has been essential. This has involved providing technical training in software, use of rubrics, sharing practice and also investing in hardware upgrades. Prior to 2014, the default PC provided to academic staff was a desk top and a single screen. It is now a laptop, docking station and two screens thus providing significantly enhanced flexibility and portability. Continued innovation in assessment and feedback is ongoing and some staff have begun trialling the use of personalized video feedback for their students.

EMA has had a significant positive impact on student satisfaction with assessment and feedback at the university. In 2013, satisfaction levels (as measured by the National Student Survey, NSS) were in the bottom quartile but in 2017 Abertay was second top in Scotland for assessment and feedback and fourth in 2018 (the score was the same for both 2017 and 2018). Specifically, feedback on the timeliness of feedback rose from $44 \%$ in 2013 to $75.6 \%$ in 2018

\section{LEARNING ANALYTICS}

In line with a growing number of universities, Abertay has become increasingly interested in maximizing use of institutional data to improve student retention, progression and attainment. We commenced an institutional learning analytics project in spring 2016, supported by JISC, by undertaking a readiness assessment in terms of systems integration, current data collection etc. The implementation roll out began in academic year 2017-18 and was done on an institutional-wide level at the outset, focussing on harvesting data from the student record system and virtual learning environment (VLE). In parallel, systematic student attendance monitoring was introduced using JISC's "study goal" app.

In order to ensure the effectiveness of the new system and alleviate potential increased workload on academic staff, two new, specific posts were created in Student Services whose roles were to proactively analyse data, identify potential students at risk and to liaise with relevant academic programme leaders/ professional services to alert them. These advisors then contact students with an offer of support. A challenge has been the variable engagement amongst students and some have expressed concerns that they are being monitored more closely by the university. However, the majority of students have welcomed the introduction of learning analytics and the university's new proactive approach to student support.

\section{INTERACTIVE LECTURES}

Improving student engagement has been a primary concern throughout all recent technology enhanced learning developments at Abertay and, coupled with new learning spaces, new opportunities for much more flexible, active learning-type pedagogies that allow staff to interact with their students in several modes even within one timetabled class, are emerging. The drivers have been to deepen our students' knowledge and understanding through collaborative working/ support with their peers and tutors. Gathering and responding to student feedback has also been an area for significant development recently. This has included formal mechanisms such as end of module surveys but also trialling new technologies to aid in-class engagement such as personal response-type systems or 'clickers'. Having trialled a couple of other systems, this academic year Abertay has been rolling out "Turning Point" in an extended pilot [7].

Turning Point allows students to either use specific response handsets, 'clickers' or they can use their own internet enabled device (smartphone, tablet, laptop). 25 academic staff from across the university have been trialling its use in various ways such as in-class quizzes (multiple choice, free text), polls, provide anonymised feedback on lectures, stimulate classroom debate and discussion. Staff have commented positively that the system lets them very quickly establish their students' understanding of particular topics in class that in turn let them adjust pace and content accordingly. Students also feel more valued as part of their learning process and feel more engaged. Students also value the ability to test their knowledge anonymously, benchmarking against their peers and this helps to build their confidence. 


\section{CONCLUSIONS}

Abertay is entering a new strategic planning phase (2020-25) and technology enhanced learning is seen as key to the success of the new strategy. Enhancing the digital literacy of our students is a strategic priority and this will also require staff development, particularly in some discipline areas. In terms of estate development, the university is moving from sand pits to wholescale upgrading of our core teaching estate with the emphasis being to support multiple modes of delivery but, in particular, active, collaborative learning.

\section{ACKNOWLEDGEMENTS}

I would like to thank my colleagues within the Teaching and Learning Enhancement team for their continued dedication, hard work and professionalism in supporting our colleagues at Abertay.

\section{REFERENCES}

[1] D. Kalkhurst "Engaging Gen Z learners and students", Pearson, March 2018. https://www.pearsoned.com/engaging-gen-z-students/.

[2] S. Kosinsky "How Generation Z is shaping the change in higher education", Forbes, July 2017. https://www.forbes.com/sites/sievakozinsky/2017/07/24/how-generation-z-is-shaping-the-changein-education/\#3f890c0d6520.

[3] Tinto, V. (1975) "Dropout from Higher Education: A Theoretical Synthesis of Recent Research" Review of Educational Research vol.45, pp.89-125.

[4] A.D. Robertson, "The Sticky Campus; improving our students' sense of belonging through active learning, coffee and cake!", Efficiency Exchange, January 2018.

http://www.efficiencyexchange.ac.uk/12560/the-sticky-campus-improving-our-students-sense-ofbelonging-through-active-learning-coffee-and-cake/

[5] A.D. Robertson, "Active Learning Design at Abertay University" in Creating the Digital Campus: Active Learning Spaces and Technology (2017). Edited by D. Peberdy. eBook ISBN- 978-09927903-1-8, print version ISBN- 978-0-9927903-2-5.

[6] Higher Education Achievement Report, HEAR. http://www.hear.ac.uk/

[7] https://www.turningtechnologies.com/ 